Article

\title{
Implementing Remote Working Policy in Corporate Offices in Thailand: Strategic Facility Management Perspective
}

\author{
Waynika Tanpipat (D), Huey Wen Lim (D) and Xiaomei Deng * \\ Department of Construction Management, Tsinghua University, Beijing 100084, China; \\ chenyy16@mails.tsinghua.edu.cn (W.T.); linhw16@tsinghua.org.cn (H.W.L.) \\ * Correspondence: dengxm@tsinghua.edu.cn; Tel.: +86-186-1062-8853
}

Citation: Tanpipat, W.; Lim, H.W.; Deng, X. Implementing Remote Working Policy in Corporate Offices in Thailand: Strategic Facility Management Perspective.

Sustainability 2021, 13, 1284.

https://doi.org/10.3390/su13031284

Academic Editor: Alex Opoku

Received: 24 December 2020

Accepted: 22 January 2021

Published: 26 January 2021

Publisher's Note: MDPI stays neutral with regard to jurisdictional claims in published maps and institutional affiliations.

Copyright: (c) 2021 by the authors. Licensee MDPI, Basel, Switzerland. This article is an open access article distributed under the terms and conditions of the Creative Commons Attribution (CC BY) license (https:/ / creativecommons.org/licenses/by/ $4.0 /)$.

\begin{abstract}
There was a sudden shift in the way people work during the COVID-19 pandemic. To keep business continuity, many organizations have implemented a remote working policy for employees to work from home. Strategic facility management (FM) acted to support remote working policies by developing organizational norms in an organization. Meanwhile, the human resource (HR) department chose to achieve business performance while remote working by gaining job motivation among employees. However, there is limited understanding of how well organizations adapted to the remote working policy, and what are the critical factors affecting their remote work performance. The present study aimed to explore the effect of organizational norms on remote working, on remote work productivity, and organizational commitment among Thai employees. The study conducted an online questionnaire survey to a total of 414 Thai employees from various corporate offices. Hierarchical component modeling was applied and achieved a good model fit on the measurement and structural models. Results indicated that organizational norm has a significant effect on perceived productivity and organizational commitment, while sustaining work demand. Moreover, employees' job motivation can sustain employees' commitment to the organization in a remote working context. These findings proposed the strategic FM guide, through which a remote working policy can further enhance FM practice.
\end{abstract}

Keywords: strategic facility management; remote working policy; organizational norms on remote working; job motivation; work demand; perceived productivity; organizational commitment

\section{Introduction}

Remote working is an innovative working model, developed since information and communication technologies (ICT) have enabled its organization. Remote working, also often referred to as telework, telecommuting, virtual work, and remote working arrangement [1,2], is defined as the shift in work style from direct management to distance management [3-5]. Remote working is not a new topic in strategic-level facility management (FM). Many organizations adopt this policy to extend the flexibility in their business towards employee performance. The reasons for implementing remote working in businesses are described in three perspectives: to respond to urban industrialization, to transform the manner of working under the rise of digitalization, and to provide flexibility to workers [5]. These objectives comprise the original design of the physical working environment, organizational norms, and supporting facilities. Facility managers must focus carefully to balance the overall transformation process to their society [6]. Though the remote working policy has been refined through strategic FM in various industries [7], there is a lack of understanding of how remote working strategies influence employees' performance capacity and psychological state [8]. The remote working strategy involved many computer-based technological operation systems and software through workplace transformation, such as communication channels, virtual conferences, and operational automation and analytics for each department [9]. Significantly, the speed of digitalization across the business due to 
COVID-19 related-change was accelerated even faster than workplace transformation in the normal situation [10]. The finding found that managing remote working applications among organizational leaders is critical but insufficient [9].

Furthermore, not every employee can achieve the flexibility from the remote work options provided by their organization. In some organizations, remote working remains similar to performing non-traditional office-based work [8]. Some employees may not be familiar with remote working tools for individual and group tasks [5]. The use of such tools requires specialized training to standardize outcomes, to be on par with on-site job outcomes [11].

The remote working initiative has become a well-known strategy since establishing the co-working space business model in Thailand in 2012 [12]. Practitioners and academic researchers in Thailand have spoken about remote working as a workplace strategy $[13,14]$. The growing popularity of co-working spaces amongst the young generation, freelancers, and small and medium-sized enterprises presented a low hierarchical environment and showed high collaborative efficiency among workers. Moreover, many international organizations in Thailand have included remote working policies in their business operation [15]. This shift harnesses an organization's optimal value, which benefits organizational brand identity, marketing communication, and work community [16].

However, the sudden change to remote work became a big challenge among organizations in Thailand when the COVID-19 pandemic was declared in March 2020 [17]. Working amidst the pandemic required physical distancing to prevent disease transmission. All organizations, in every impacted sector, were forced to embrace remote working protocol to prevent workplace density. Employees were kept safe by launching a 'work from home (WFH)' policy. In such conditions, organizations considered reducing unnecessary expenses, such as office rent and building maintenance costs [18]. PwC stated that 20\% of Thai companies practiced working from home during the COVID-19 pandemic. Some companies asked their staff to undertake WFH at least two days per week and go to the office only if necessary, such as conferences or workshops [19]. This period of pandemic became a massive experiment of the remote work operation. Employees who have never worked remotely under normal circumstances were required to do so during this crisis [8]. Inexperienced employees have become an unexpected primary consideration before implementing remote working. Additionally, many sectors faced widespread rises and declines in work demand [20]. These dramatic changes significantly influenced individuals' attitudes in work continuity, job performance, and perceived productivity [21-23]. In this unstable and uncertain situation, considerable resources and work caused difficulties in management. Entire teams and leaders needed to perform multiple disciplines and make decisions quickly to collaborate with suppliers and customers-all to keep the business running [24]. Employees must face an inconvenient psychological strain, which reduces job motivation to the workplace and organizational commitment $[25,26]$. As such, the organizations are challenged with the management of work demand while sustaining employees' productivity and commitment $[27,28]$.

With the challenges faced by organizations, FM that mainly focused on physical asset management falls short on the consideration of human resource (HR) concerns. HR functions, such as training and service, become the required solution to maintain employees' work processes and gain the most efficiency from organizational human assets during pre- and post-workplace transformation $[29,30]$. The focus on remote work adoption in the existing FM framework has been derived by organizational context and environmental context. HR practices at organizational and group level become the following stage of remote working implementation. The individual outcomes are only explored after achieving remote work practice [31]. Based on the previous issues, the main gap of facility management approach on workplace transformation is not noticing HR drivers at the beginning of remote working implementation. Employees' negative outcomes from remote work implementation may increase and affect organizational cost [4]. 
Therefore, the present study aimed to explore the mediating effect of organizational norms on remote working and job motivation on the relationship between work demand and employees' perceived productivity and commitment. The study's finding would increase awareness among top management to consider the organizational norm of remote working and job motivation as a workplace strategy to stabilize the quality of work demands, perceived productivity, and employee's organizational commitment. In contrast, without considering human resource and physical asset management for remote working transformation, organizations may experience an unexpectedly negative outcome from overall employee performance.

\subsection{Literature Review}

Implementing remote working in an organization is monitored from various procedures, and overall work outcome and job satisfaction after the implementation are measured through Human Resource Management (HRM) or self-evaluation [32]. However, the measurement of remote working efficiency receives little attention in FM practices [33]. Tucker and Pitt [34] remarked that satisfaction measurement on FM literature and practices is limited, even if understanding users' perceptions could add value to an organization and its service delivery. Some psychological outcomes from remote work initiatives on employees could affect business continuity and bring about remote working study concerns. Strategic FM managers could inspire new measurement factors for a remote working policy, influence the right working environment, and efficiently sustain organizational assets. The main variables will be detailed in this section.

\subsubsection{Perceived Productivity}

Employees' remote work productivity can be influenced by leadership and organizational support [35]. Sullivan and Khazanchi explained that effective remote work productivity required high and constructive communication to sustain the working relationship among the organization's members [36,37]. However, previous studies showed that the communication between colleagues via virtual connection was often less than the communication among colleagues who work on-site [38-40]. Without a precedent, and leadership initiative, employees may have difficulty initiating work-related conversations. Besides, remote working involves IT and the operation of devices such as personal computers, laptops, or smartphones, while employees are required to engage in collaborative activities when remote working. The organizations need to provide management support via those facilities [41]. Nevertheless, remote working showed an impact on employees' concentration, affecting work productivity [38]. The lack of control of the remote working environment, such as poor internet connection [42], distractions from the physical workplace environment, and interruptions from non-work-related calls and email [43], can affect employees' concentration work.

\subsubsection{Organizational Commitment}

Implementing a remote working policy can affect employees' commitment to the organization $[40,44]$. Organizational commitment in remote work studies is defined as a psychological state the justifies an employee's relationship with the organization, where it has implications for the decision to retain membership in the organization $[45,46]$. Allen and Meyer [47] explained three main components of organizational commitment: (1) affective commitment that is demonstrated by individuals' emotional attachment to an organization; (2) continuance commitment that represents an employee's need to remain in an organization owing to perceived costs to leave; and (3) normative commitment that presents a set of cultural factors that keep the employees in an organization [31,48]. Previous multicultural studies showed that the significance of employees' attention to their workplace, especially workplace arrangement policy based on building trust between managers and employees [49,50], had been extensively covered [46]. Nonetheless, exciting issues emerged in examining employees' commitment in different cultures; findings demonstrated different 
responses from each organizational commitment component. Veldhoven explained that affective commitment and continuance commitment could predict participative leadership and organizational effectiveness [28]. Machokoto examined employees' commitment during the COVID-19 outbreak and found that continuance commitment displayed a significant role in the emotional cost during the challenging circumstance [51]. The remote working context also challenges organizational commitment. Without controlling for pace and amount of work, employees could exhibit lower performance and reduced organizational commitment and incorporate perspective to their organizations [40].

\subsubsection{Work Demand}

Work demand refers to the workload and job stress given to the employees [43]. Many academic reviews described work demand as one of the significant factors in the 'Job Demands-Resources Model' proposed by Bakker which performed the concept of psychological and physical capacity of work to achieve work goals $[28,52,53]$. The shift of work demand in an organization frequently occurs by demographic change and, consequently, impacts workplace transformation to sustain their optimal business continuity [54]. During the COVID-19 pandemic, the organization faced massive disruptions in the workforce, global supply chain, and demand for services, which caused the increase in work demand and the requirement of the next level in architecting remote work technology [9]. With the increasing work demand, employees may feel slightly challenged and motivated to perform [28]. However, the sudden change in work demand can also cause the employees to experience emotional exhaustion and losing work-life balance. Consequently, work demand may wear-out employees' mental attention from attaining their work assignments [55]. Gadeyne spotted that work demand showed an opposite effect on employees' productivity in a remote working context. Employees showed reduced productivity when working remotely with an increasing work demand, due to the difficulty of compensating for ICT-use during personal and working hours [43]. In addition, Grant also suggested that work demand acts as an external stressor to the employees when the supervisors or organization issued work assignments and expectations for completion, affecting the organizational commitment of remote working employees [40]. On the contrary, with deep concern about creating efficient work demand, an organization can cultivate a sustainable organizational system [56] and maintain resiliency [57]. During a crisis, the organization could build employees' confidence by remaining stable on work demand with potential communication. In addition, organizations with a high response on work demand also have the potential to save lives and keep efficient employee's recruiting and retention [24]. Therefore, this study hypothesized the following.

Hypothesis 1A. Work demand positively affects perceived productivity.

Hypothesis 1B. Work demand positively affects organizational commitment.

\subsubsection{Organizational Norms on Remote Working as a Mediator}

Organizational norms refer to the shared values and behaviours among an organization's members to attain a common goal $[45,58]$. Today, remote working arrangement flexibility has become a primary consideration for any future-transformed organization, and such flexibility is particularly relevant in the new norm emerging from the demographic change in the last few decades [50,59]. Therefore, organizational norms on remote working (hereafter referred to as 'organizational norms') have provided a solution to organization transformation from the traditional organizational culture and encouraged employees to approach tasks with productivity and flexibility [59]. According to Deloitte, the concept of today's organizational norms can be explained with three core elements: (1) working remotely, particularly from home; (2) balancing between the team, customers, and home; and (3) leveraging technological facilitation to enable continuous collaboration and communication. These elements encouraged the work capacity of employees to empower business 
continuity and sustainability of workplace transformation. According to the FM approach, organizational norms highlighted not only the service support from FM teams but also the strategic alignment among the employees in an organization [7]. Ninaus explained that employees who work remotely showed reduced perceived productivity due to the poor remote working application in their organization [25]. Organizational norms that showed insufficient remote working support would raise negative consequences to organizational operation by increasing job stress and reducing organizational commitment [60].

On the other hand, Szczepańska and Woszczyna revealed that organizational norms that provide positive remote working support improved employees' organizational commitment [61]. During COVID-19, organizational norms respond to implementing new culture and context to remain operational and ensure work demand and continuity [59]. Therefore, this study hypothesized the following.

Hypothesis 1C. Organizational norms on remote working mediate the relationship between work demand and perceived productivity.

Hypothesis 1D. Organizational norms on remote working mediate the relationship between work demand and organizational commitment.

\subsubsection{Job Motivation as a Mediator}

The definition of job motivation is theorized from the Job Characteristic Model by Hackman and Oldham [62]. It refers to employees' self-generated motivation from the internal experience when they feel fully responsible for work outcome on a meaningful task and finds out how well they perform. During accelerated organizational transformation, employees can experience psychological and physical impacts and these influence their job motivation. Firstly, the economic instability and technological disruption that lead to a change in work demand created fear among employees [63]. Baert, S., et al. conducted research and found that employees' risk from job loss during the crisis, such as the COVID-19 pandemic, increased by $49.9 \%$, and their fear of an impact on their personal job motivation rose by $27.5 \%$ [64]. Secondly, the physical change of working facility, forming the new organizational norms on remote working, challenged employees' performance amidst distractions in their new work environment, which may consequently reduce their job motivation [65]. The International Labor Organization suggested organizations should sustain their employees' motivation and well-being by providing support through HR and FM teams to ensure the level of productivity and the functioning of services [8]. Understanding the requirement of remote working from HR, including knowledge, regulatory, and the legislative environment, is essential for delivering technical and process-related services from FM to motivate employees at the organization [7]. Job motivation plays an important mediator role in the relationship between work characteristics and job performance [66]. Past research has found the significant effect of job motivation on employees' job satisfaction, employees' retention, organizational engagement, and outcome [67]. Therefore, the present study examined job motivation as the mediator variable in the relationship proposed from the previous hypotheses:

Hypothesis 2A. Job motivation mediates the relationship between work demand (WD) and perceived productivity.

Hypothesis 2B. Job motivation mediates the relationship between work demand (WD) and organizational commitment.

Hypothesis 2C. Job motivation mediates the relationship between organizational norms on remote working and perceived productivity. 
Hypothesis 2D. Job motivation mediates the relationship between organizational norms on remote working and organizational commitment.

In summary, the present study aimed to explore the impact of work demand on employees' perceived productivity and organizational commitment, mediated by organizational norms and job motivation. Figure 1 illustrates the relations between work demand, organizational norms, job motivation, perceived productivity, and organizational commitment.

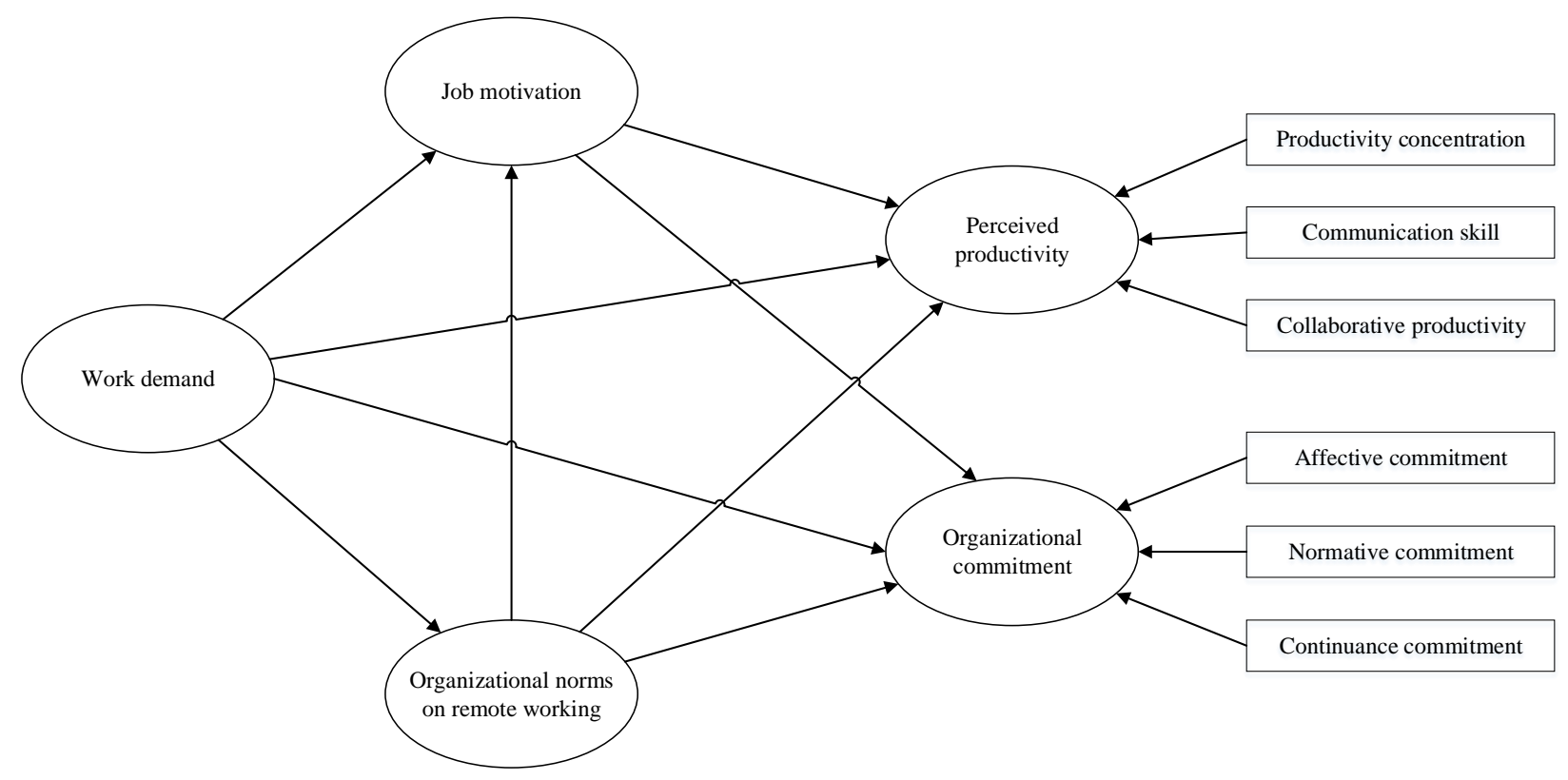

Figure 1. Hypothesized model in the present study.

\section{Materials and Methods}

This study was conducted in corporate organizations in Bangkok, Thailand. The questionnaire was first developed and validated through an interview with nine experts in FM and Thailand's property management services. The questionnaire was revised according to experts' feedback and then distributed to participants using an online survey. A total of 414 valid responses from various sectors were received. The hierarchical component analysis was applied first to assess the measurement model and eliminate the insignificant measurement items. After validation of the measurement model, the structural model of causality relationships between factors was examined. The findings are discussed in the discussion section.

\subsection{Questionnaire Development}

Before examining the mediating effect of the organizational norm on remote working and job motivation on the relationship between work demand, perceived productivity, and organizational commitment, the measurement tool for evaluating remote working implementation should be developed. Deloitte [59] suggested that organizations and leaders must implement new organizational norms for remote working to remain operational and ensure continuity. Sirikrai [68] proposed the Kilmann-Saxton Culture-Gap survey's measurement tools to measure perceived organizational support in role management and functional management, including task support, task innovation, social relation, and personal freedom. Wojcak et al. [69] also proposed that a leader's role, including social influence, voluntary action, and followers' behavior, could internalize the organizational norm system and change employee behavior. Combining all the other assessment tools, most of these tools have focused on the norm-based organizational measurement to address the significant implication of the sudden shift to remote work. 
To assess job motivation's mediating effect in an organizational context, the Motivating Potential Score (MPS) index could be a unique HR tool to predict job potential to motivate employees [70]. The MPS index uses a score-based summary from the job diagnostic survey established by Hackman and Oldham, which is widely used in human resources and organizational development [71]. The index computes task-related score variable, that is, the average of job variety (JV), task identity (TI), and task significance (TS) multiplied by autonomy (A) and feedback (F).

$$
\mathrm{MPS}=([\mathrm{JV}+\mathrm{TI}+\mathrm{TS}]) / 3) \times \mathrm{A} \times \mathrm{F}
$$

The MPS index is divided into three levels: (1) low-motivating job (score below than $40 \%$ ), (2) moderate-motivating job (score of 40-70\%), and (3) high-motivating job (score more than 70\%). The proposed Cronbach's alpha for reliability evaluation is 0.79 .

Veldhovan et al. [28] developed 'The Questionnaire on the Experience and Evaluation of Work'(QEEW 2.0), which interpreted from a 'Job Demands-Resources Model' perspective [52] to measure work demand, including pace and amount of work, emotional workload, mental workload, physical effort, and role conflict. This evaluating subject could assess and measure the challenge at work and development opportunity in a specific working context. While these evaluation tools offer useful work demand measures, they are not considered the management practices that may affect individual work demand during remote working. The International Labor Organization (ILO) [8] stated clearly that employees and leaders might confront the increase in work demands when their entire teams worked remotely and suggested that management practices must be addressed to the remote work environment prioritization, workload, policy arrangement, and performance management.

To measure perceived productivity in remote working implementation, Mckinsey and Company suggested assessing two main focuses, namely, communication skills and collaborative productivity [24]. Van der Voordt [14] proposed the positive and negative effects of workplace innovation on communication quality. Sveiby and Simons [72] developed the Collaborative Climate Survey to measure the ability to work collaboratively with participants. Meanwhile, See [21] and Silva-C [11] also suggested that productivity concentration can be affected by different work environments and the increase in additional workload during remote work. Combining all these assessment tools, these consider the measuring perceived productivity, especially in the remote working context-related environment.

Mee Choo and Michielsens [45,46] suggested measuring organizational commitment to evaluate employees' psychological state during remote work with the organization. To measure organizational commitment, Allen and Meyer [48] developed the measurement of organizational commitment into the three dimensions of psychological commitment, namely, affective commitment, continuance commitment, and normative commitment. The three organizational commitment states have been adopted widely in organizational and human resource practice in different regions and the office context [46].

Based on these measurement tools and previous studies, the authors drafted a questionnaire into a total of 88 items, including 17 items on demography groups, 9 items on the organizational norm (perceived organizational support and leadership support), 21 items on perceived productivity (collaborative productivity, communication skill, and productivity concentration), 11 items on the work demand, 15 items on organizational commitment (affective commitment, continuance commitment, and normative commitment), and 15 items on job motivation (the motivation potential score index). Participants were requested to evaluate their level of agreement on a Likert scale ranging from 1 for 'strongly disagree' or 'the least' to 7 for 'strongly agree' or 'the highest.'

\subsection{Interview with Experts}

Experts were interviewed to ensure the questionnaires' rationality and relevance to the current remote working policy in Thailand organizations. Table 1 shows the background of the nine experts in FM and property management. They were directors, presidents, 
workplace strategists, and top executives from companies A, B, and C, respectively, with work experiences ranging from 5 to 20 years. The experts from company A were the consultants specializing in remote working strategy. All companies had implemented remote working into facility management. Therefore, they were able to provide valid and reliable information and feedback regarding remote working. The experts advised adding essential items and eliminating irrelevant items from the questionnaire. After the interview, the questionnaires were finalized into a total of 58 items, including 11 items on the work demand, 9 items on organizational norms, 12 items on perceived productivity, 11 items on organizational commitment, and 15 items on job motivation based on the MPS index. An 11-item demographic questionnaire was also prepared.

Table 1. Details of experts who were interviewed.

\begin{tabular}{|c|c|c|c|c|c|}
\hline No. & Company & Sector & Department & Position & Experience \\
\hline 1 & A & $\begin{array}{l}\text { Property management and facility } \\
\text { management service provider }\end{array}$ & Top management & $\begin{array}{l}\text { Director, head of } \\
\text { workplace strategist }\end{array}$ & 17 years \\
\hline 2 & A & $\begin{array}{l}\text { Property management and facility } \\
\text { management service provider }\end{array}$ & $\begin{array}{l}\text { Workplace strategy } \\
\text { and design }\end{array}$ & $\begin{array}{l}\text { Senior workplace } \\
\text { strategist }\end{array}$ & 6 years \\
\hline 3 & A & $\begin{array}{l}\text { Property management and facility } \\
\text { management service provider }\end{array}$ & $\begin{array}{l}\text { Workplace strategy } \\
\text { and design }\end{array}$ & Workplace strategist & 5 years \\
\hline 4 & B & Facility management & Top management & President & 5 years \\
\hline 5 & B & Facility management & Top management & Executive committee & 5 years \\
\hline 6 & C & $\begin{array}{l}\text { Property development and } \\
\text { architectural design }\end{array}$ & Top management & Executive vice president & 20 years \\
\hline 7 & C & $\begin{array}{l}\text { Property development and } \\
\text { architectural design }\end{array}$ & Top management & Vice president & 17 years \\
\hline 8 & $\mathrm{C}$ & $\begin{array}{l}\text { Property development and } \\
\text { architectural design }\end{array}$ & $\begin{array}{l}\text { Research and } \\
\text { development }\end{array}$ & Senior developer & 9 years \\
\hline 9 & $\mathrm{C}$ & $\begin{array}{l}\text { Property development and } \\
\text { architectural design }\end{array}$ & $\begin{array}{l}\text { Research and } \\
\text { development }\end{array}$ & Senior developer & 7 years \\
\hline
\end{tabular}

\subsection{Questionnaire Survey}

An online survey was distributed to 1000 Thai employees of international and local organizations located in the city center of Bangkok, which has been designated as a lockdown zone (meaning that there were more than 100 cases of COVID-19 have been confirmed in the area). The respondents must possess at least one year of experience in a corporate office in any industry field. A total of 414 responses were valid, indicating a $41.4 \%$ effective response rate. Table 2 shows that, amongst respondents, $41.5 \%$ were male, and $58.5 \%$ were female; furthermore, $80 \%$ of them were between the ages of 26 to 40 . Respondents were from various sectors, including agriculture and food (5.3\%), consumer products $(4.8 \%)$, finance $(10.4 \%)$, industrial $(7.0 \%)$, property and construction (22.7\%), energy resources (2.9\%), services $(19.8 \%)$, technology $(8.0 \%)$, education $(14.5 \%)$, and government $(4.6 \%)$. The majority $(72.2 \%)$ were non-management employees, 12.1 and $15.7 \%$ were in middle and top management positions, respectively. Only $7.2 \%$ reported that remote working arrangement was stipulated in their job contract before the COVID-19 pandemic. However, during the COVID-19 pandemic, 40.6\% of respondents reported working full-time from home, $31.4 \%$ of them reported working at the office only when necessary, and $22.2 \%$ of them were required to work at the office at least three times a week or all week with physical distancing practices. In terms of living conditions, $53.1 \%$ of respondents reported living with family without children, $20.3 \%$ were living with children, $19.3 \%$ were living alone, and $7.2 \%$ lived with friends or others. Finally, $57 \%$ of them earned a monthly income higher than 40,000 baht. 
Table 2. Demographic information of survey respondents.

\begin{tabular}{|c|c|}
\hline Characteristics & \\
\hline \multicolumn{2}{|l|}{ Gender } \\
\hline Male & $41.5 \%(172)$ \\
\hline Female & $58.5 \%(242)$ \\
\hline \multicolumn{2}{|l|}{ Age } \\
\hline 18-25 years old & $6.0 \%(25)$ \\
\hline $26-40$ years old & $80.0 \%(331)$ \\
\hline $41-55$ years old & $12.8 \%(53)$ \\
\hline$>55$ years old & $1.2 \%(5)$ \\
\hline \multicolumn{2}{|l|}{ Occupational sectors } \\
\hline Agriculture and food & $5.3 \%(22)$ \\
\hline Consumer products & $4.8 \%(20)$ \\
\hline Finance & $10.4 \%(43)$ \\
\hline Industrial & $7.0 \%(29)$ \\
\hline Property and construction & $22.7 \%(94)$ \\
\hline Energy resources & $2.9 \%(12)$ \\
\hline Services & $19.8 \%(82)$ \\
\hline Technology & $8.0 \%(33)$ \\
\hline Education & $14.5 \%(60)$ \\
\hline Government & $4.6 \%(19)$ \\
\hline \multicolumn{2}{|l|}{ Job position } \\
\hline Employee (non-management) & $72.2 \%(299)$ \\
\hline Middle management & $12.1 \%(50)$ \\
\hline Top management & $15.7 \%(65)$ \\
\hline \multicolumn{2}{|l|}{ Income (in baht) } \\
\hline $10,000-20,000 /$ month & $11.1 \%(46)$ \\
\hline $20,001-40,000 /$ month & $31.9 \%(132)$ \\
\hline$>40,000 /$ month & $57.0 \%(236)$ \\
\hline \multicolumn{2}{|l|}{ Current living condition } \\
\hline Living alone & $19.3 \%(80)$ \\
\hline Living with friends or others & $7.2 \%(30)$ \\
\hline Living with family without children & $53.1 \%(220)$ \\
\hline Living with family with children & $20.3 \%(84)$ \\
\hline \multicolumn{2}{|l|}{ Remote working arrangement in job contract } \\
\hline Yes & $7.2 \%(30)$ \\
\hline No & $73.9 \%(306)$ \\
\hline Unknown & $18.8 \%(78)$ \\
\hline \multicolumn{2}{|l|}{ Working arrangement during COVID-19 period } \\
\hline Working full-time from home & $40.6 \%(168)$ \\
\hline Working full-time from home and working at the office when necessary & $31.4 \%(130)$ \\
\hline $\begin{array}{c}\text { Working at the office at least three times per week and practices physical } \\
\text { distancing at the office }\end{array}$ & $14 \%(58)$ \\
\hline Working full-time at the office while observing physical distancing & $8.2 \%(34)$ \\
\hline Others & $5.8 \%(24)$ \\
\hline
\end{tabular}

\section{Results}

This study applied partial least squares structural equation modeling (PLS-SEM) for hierarchical component analysis. Analysis of variance (ANOVA) test was first conducted to identify the control variables included in the model analysis. To assess the measurement model, exploratory factor analysis (EFA) was used to identify factors and items of each factor with adequate loadings. Overall, 12 items were dropped because of unsatisfactory factor loading $(<0.5)$. Confirmatory factor analysis (CFA) confirmed the adequate convergent validity and discriminant validity of the reflective measurement model. Finally, the structural model was examined. The good model fit was confirmed by Heterotraitmonotrait (HTMT) ratio. Common method bias was identified by full collinearity test. The proposed model, and the significant relationships in the model are discussed further. 
Statistic Package for the Social Sciences (SPSS) statistics 23 and SmartPLS 3 software were used for data analysis.

\subsection{Control Variables}

An ANOVA test was conducted to identify respondents' characteristics that may affect the constructs. Table 3 shows that respondents in different age groups had significant differences in the level of communication skill, normative commitment, and continuance commitment.

Table 3. ANOVA test.

\begin{tabular}{|c|c|c|c|c|c|c|}
\hline Constructs & Age & Job & Income & $\begin{array}{l}\text { Current Living } \\
\text { Condition }\end{array}$ & $\begin{array}{l}\text { Remote Working } \\
\text { Policy in the } \\
\text { Organization }\end{array}$ & $\begin{array}{l}\text { Remote Working } \\
\text { During COVID-19 }\end{array}$ \\
\hline Work demand & 0.645 & 1.940 & 3.834 * & 1.149 & 1.541 & $4.022 * *$ \\
\hline $\begin{array}{c}\text { Organizational } \\
\text { norms }\end{array}$ & 0.601 & 0.906 & $3.107^{*}$ & 0.239 & $12.641^{* * *}$ & $8.063^{* * *}$ \\
\hline $\begin{array}{l}\text { Productivity } \\
\text { concentration }\end{array}$ & 0.563 & 2.078 & $4.235 *$ & 1.022 & 0.435 & $5.694^{* * *}$ \\
\hline $\begin{array}{l}\text { Collaborative } \\
\text { productivity }\end{array}$ & 1.188 & 1.893 & 3.908 * & 0.492 & 0.254 & $6.331^{* * *}$ \\
\hline $\begin{array}{l}\text { Communication } \\
\text { skill }\end{array}$ & $3.086^{*}$ & $4.18 *$ & 2.478 & $2.823 *$ & 0.656 & $8.202^{* * *}$ \\
\hline $\begin{array}{c}\text { Affective } \\
\text { commitment }\end{array}$ & 0.824 & $4.616^{* *}$ & 1.789 & $4.135^{* *}$ & 1.864 & $3.056^{*}$ \\
\hline $\begin{array}{l}\text { Normative } \\
\text { Commitment }\end{array}$ & $1.804^{*}$ & $3.282 * * *$ & $2.015^{* *}$ & 0.823 & 1.534 & 1.451 \\
\hline $\begin{array}{l}\text { Continuance } \\
\text { Commitment }\end{array}$ & $5.587^{* * *}$ & $9.627^{* * *}$ & 1.378 & 2.419 & 0.751 & 0.645 \\
\hline Job Motivation & 0.119 & 2.407 & $8.299 * * *$ & $2.663 *$ & $5.580 * *$ & 0.878 \\
\hline
\end{tabular}

Respondents in different job levels significantly varied in their communication skills, affective commitment, normative commitment, and continuance commitment. Older employees with high job positions are concerned with their individual ability to influence others' behaviour [73]. This concern brings about the imperative to take care of employees who relate to organizational commitment influence, through which employees increase their emotional bond to the organization [31].

By contrast, respondents with different income levels significantly varied in their work demand, organizational norms, productivity concentration, collaborative productivity, normative commitment, and job motivation. Income level presented the ability to work potential and the number of job-related outcomes [74].

Respondents with different living conditions showed significant differences in their communication skills, affective commitment, and job motivation. Moreover, respondents with the existing remote working policy in the organization exhibited significantly different organizational norms and job motivation compared with those without. This is because the standard living arrangement [75] of employees who preferred remote working implementation could present different impacts on employees' performance [44] and skills development [76].

After the outbreak of COVID-19, respondents who were provided with remote working arrangements by their companies showed significant differences in work demand, organizational norms, productivity concentration, collaborative productivity, communication skill, and affective commitment. Therefore, the results have proven that remote working arrangements could affect employees' work both positively and negatively on work performance $[44,77]$. The productivity outcome from remote working implementation could be the significant measurement for working context study, as it showed the essential result on remote working $[25,41]$. 


\subsection{Measurement Model Assessment}

This study applied a two-stage approach for hierarchical component analysis proposed by Ringle et al. (2012) [78]. Before examining the structural relationship between factors, the measurement model was assessed to ensure reliable and valid items gauging their constructs. EFA was first conducted to identify the reflective constructs and items used in the surveys. Principle Component Analysis (PCA) and Promax rotation with an eigenvalue greater than one was applied for the extraction of factors $[79,80]$. The factor analysis showed distinct and reliable factors when the Kaiser-Meyer-Olkin value was 0.873 and $p<0.001$, which was above the recommended value of 0.60 [81]. Each item's factor loading should be greater than 0.50, with no major cross-loadings [82]. As a result, work demand (WD) items; WD1, WD5-7, WD10-11, organizational norms (ON) items; ON1-2, affective commitment (AC) items; AC1-2, AC5, and continuance-normative commitment $(C C)$ item; $C C 2$ were dropped (factor loading $<0.5$ ). The pattern matrix identified seven reflective constructs, with continuance commitment and normative commitment clustered into one construct. The combined effects of commitment constructs are aligned with the past literature recommended that combining constructs can measure work behavior and outcome $[83,84]$. Consequently, items of both constructs were combined and referred to as continuance-normative commitment. Overall, seven reflective constructs with clustered loading items were above the value of 0.5 , and no major cross-loading was found between work demand, organizational norms, productivity concentration, collaborative productivity, communication skill, affective commitment, and continuance-normative commitment.

CFA was performed to validate the measurement model of reflective constructs by assessing the convergent validity and discriminant validity. The factor loadings, composite reliability (CR), and average variance extracted (AVE) values were analyzed to verify convergent validity. Following the recommendation by Hair et al. (2010), all items showed factor loadings greater than 0.5 , except for WD8-9 and CC1, which were consequently eliminated from the model. Nunnally and Bernstein (1994) recommended a CR value above 0.7 to be a more stringent criterion of internal consistency reliability than Cronbach's alpha [85]. Fornell and Larcker proposed that the threshold value for AVE should be greater than 0.5 [86]. Table 4 shows that the AVE and CR of each construct satisfied the criteria; hence, the convergent validity is adequate.

Table 4. AVE, CR and discriminant validity of the reflective constructs.

\begin{tabular}{lcccccccc}
\hline \multicolumn{1}{c}{ Constructs } & AVE & CR & $\mathbf{1}$ & $\mathbf{2}$ & $\mathbf{3}$ & $\mathbf{4}$ & $\mathbf{5}$ & $\mathbf{6}$ \\
\hline 1. Affective Commitment & 0.664 & 0.798 & - & & & & & \\
2. Collaborative & 0.747 & 0.922 & 0.088 & - & & & & \\
Productivity & 0.822 & 0.948 & 0.11 & 0.702 & - & & & \\
3. Communication Skill & 0.556 & 0.829 & 0.46 & 0.072 & 0.075 & - & & - \\
4. Continuance-Normative & 0.646 & 0.927 & 0.136 & 0.269 & 0.269 & 0.299 & - & \\
Commitment & 0.62 & 0.865 & 0.102 & 0.589 & 0.85 & 0.101 & 0.257 & - \\
5. Organizational Norms & 0.54 & 0.777 & 0.096 & 0.579 & 0.652 & 0.169 & 0.296 & 0.584 \\
6. Productivity & Concentration & 7. Work Demand &
\end{tabular}

Note: CR, composite reliability; AVE, average variance extracted. The square root of AVE in parentheses, $p<0.01$. HTMT, heterotraitmonotrait ratio threshold value $<0.900$.

The discriminant validity was assessed by using the heterotrait-monotrait (HTMT) ratio approach. Table 4 shows the correlation matrix for the constructs with the diagonal elements replaced by the square roots of AVE. The square roots of AVE had a higher value than the correlations between these constructs and other constructs, thereby indicating good discriminant validity, as suggested by Hair et al. [87]. Henseler et al. [88,89] proposed a HTMT threshold value below than 0.900 for structural models with cognitive satisfaction. 
Thus, the constructs in the reflective measurement model were considered adequate. Appendix A presents the validated set of questionnaires.

To identify the common method bias in this studied model, a full collinearity test was performed. Following the recommendation by Kock [90], the Variance Inflation Factors (VIFs) values of latent variables should be lower than or equal to the threshold of 3.3. Table 5 shows that all latent variables satisfied the criteria; therefore, it is concluded that common method bias was not detected.

Table 5. Full Collinearity VIFs.

\begin{tabular}{lccccc}
\hline \multicolumn{1}{c}{ Constructs } & $\mathbf{1}$ & $\mathbf{2}$ & $\mathbf{3}$ & $\mathbf{4}$ & $\mathbf{5}$ \\
\hline 1. Job Motivation & - & 1.062 & 1.091 & 1.081 & 1.078 \\
2. Organizational & 1.073 & - & 1.05 & 1.102 & 1.099 \\
Commitment & 1.158 & 1.103 & - & 1.126 & 1.146 \\
3. Organizational Norm & 1.495 & 1.508 & 1.467 & - & 1.12 \\
4. Perceived productivity & 1.481 & 1.495 & 1.483 & 1.113 & - \\
5. Work demand & & & & & \\
\hline
\end{tabular}

Note: The Variance Inflation Factors (VIFs) $\leq 3.3$.

\subsection{Structural Model Assessment}

After validating the measurement models, the latent variable score of the lower-order constructs (LOCs) were obtained as indicators in the higher-order constructs' (HOC) measurement in the structural model. Bootstrapping of 5000 samples was conducted to analyze the significance of the path coefficients between constructs. The results confirmed that the three LOCs to their HOC perceived productivity at a $t$ value above 1.96. Communication skill exhibited the highest weight (0.621), followed by productivity concentration (0.515). Collaboration productivity showed an extremely low weight (0.002), and affective commitment and continuance-normative commitment were attributed significantly to their HOC organizational commitment at $t$ value above 1.96. Continuance-normative commitment yielded a higher weight (0.750) than affective commitment (0.431).

Following the approach by Hair et al. [91], the coefficient of determination $\left(R^{2}\right)$, effect size $\left(f^{2}\right)$, and predictive relevance $\left(q^{2}\right)$ of the structural model were examined. $R^{2}$ explains the predictive power of the model. As recommended by Henseler et al. [92] and Hair et al. [93], the endogenous constructs exhibited an $R^{2}$ value of $0.75,0.50$, and 0.25 , which are interpreted as substantial, moderate, and weak constructs, respectively. In Figure 2, the $R^{2}$ values of organizational norms $\left(R^{2}=0.064\right)$, organizational commitment $\left(R^{2}=0.090\right)$, and job motivation $\left(R^{2}=0.046\right)$ were considered weak values and perceived productivity $\left(R^{2}=0.359\right)$ was considered a moderate value. These constructs have shown acceptable predictive power in the model.

The effect sizes of these significant constructs in the model $\left(f^{2}\right)$ were assessed to determine the degree of impact that an exogenous latent construct has on the endogenous latent construct [91]. When the exogenous construct was excluded from the path model, the change in the $R^{2}$ value was observed, and the effect sizes of the exogenous latent constructs were estimated and compared [91]. Cohen [94] suggested a guideline measure for the effect size of $f^{2}$, in which 0.35 indicates a large effect, 0.15 indicates a medium effect, and 0.02 indicates a small effect. Thereafter, a blindfolding procedure was applied to examine the model's predictive relevance, with an omission distance set to 7 to assess the cross-validated redundancy measures for each endogenous construct [95]. Henseler et al. and Hair et al. stated that the values of $0.35,0.15$, and 0.02 would indicate a large, medium, and small predictive relevance for the endogenous construct [82,91,92,95].

Table 6 shows that work demand exhibited a strong effect size and predictive relevance on perceived productivity $\left(f^{2}=0.437, q^{2}=0.428\right)$ greater than that on organizational norms $\left(f^{2}=0.068, q^{2}=0.066\right)$ and job motivation $\left(f^{2}=0.048, q^{2}=0.044\right)$. JM showed a weak effect size and predictive relevance on organizational commitment $\left(f^{2}=0.031, q^{2}=\right.$ 0.029). Similarly, organizational norms had a weak effect size and predictive relevance on 
organizational commitment $\left(f^{2}=0.057, q^{2}=0.052\right)$ and perceived productivity $\left(f^{2}=0.075\right.$, $\left.q^{2}=0.025\right)$.

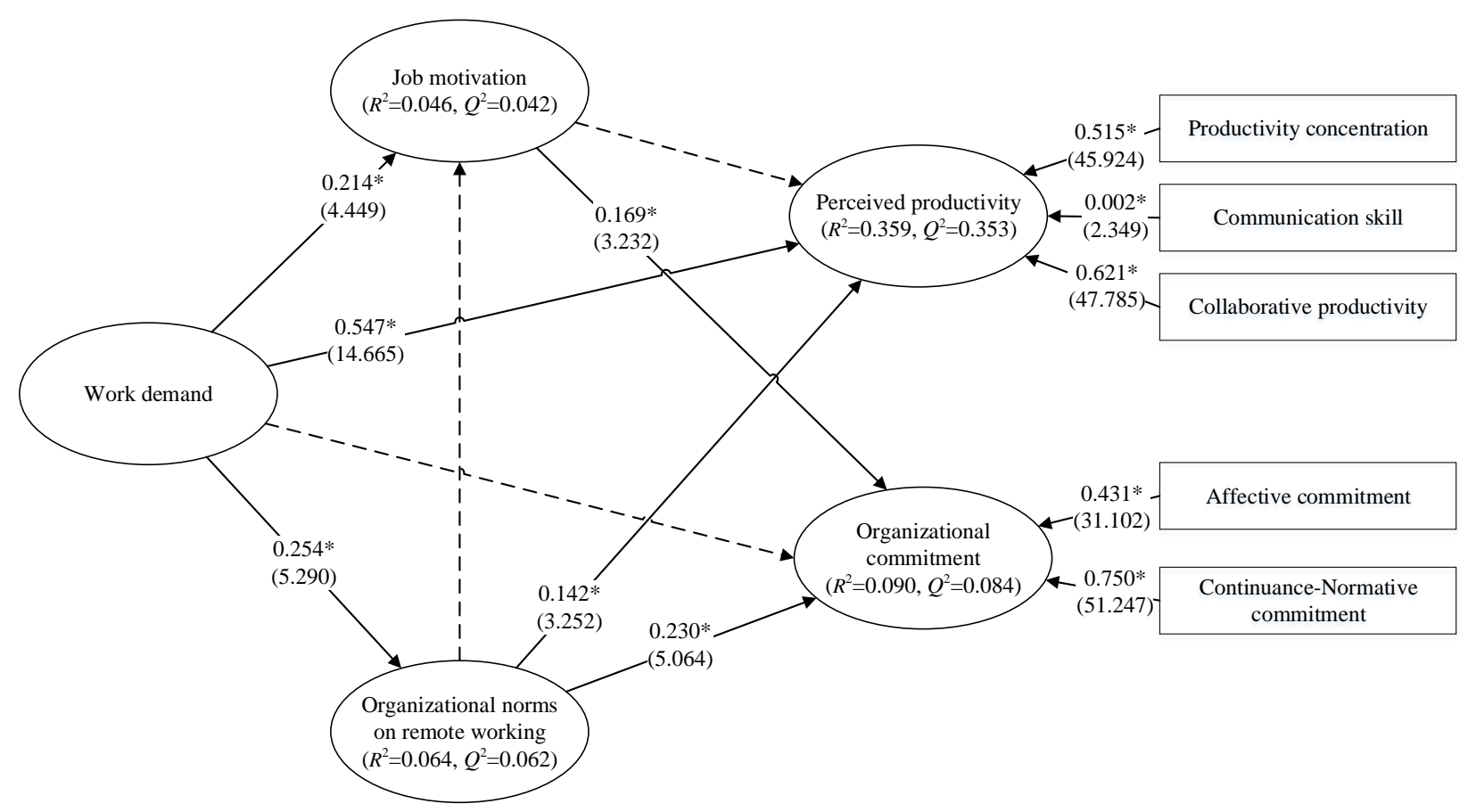

Figure 2. Structural model, path coefficient and $t$-value in parentheses, significant $t$ value at $>1.96,{ }^{*} p<0.001$.

Table 6. Assessment of path coefficient, effect size, and predictive relevance.

\begin{tabular}{cccccccc}
\hline Relationships & $\boldsymbol{\beta}$ & Std. Error & $\boldsymbol{t}$ Value & $f^{\mathbf{2}}$ & $\boldsymbol{q}^{\mathbf{2}}$ & $\mathbf{5 \%}$ & $\mathbf{9 5 \%}$ \\
\hline Work demand -> Organizational norms & 0.254 & 0.048 & 5.290 & 0.068 & 0.066 & 0.177 & 0.339 \\
Work demand -> Perceived productivity & 0.547 & 0.037 & 14.665 & 0.437 & 0.428 & 0.482 & 0.607 \\
$\quad$ Work demand -> Job motivation & 0.214 & 0.048 & 4.449 & 0.048 & 0.044 & 0.137 & 0.285 \\
$\quad \begin{array}{c}\text { Job motivation -> Organizational } \\
\text { commitment }\end{array}$ & 0.169 & 0.052 & 3.232 & 0.031 & 0.029 & 0.085 & 0.252 \\
$\begin{array}{c}\text { Organizational norms -> Organizational } \\
\text { commitment }\end{array}$ & 0.230 & 0.046 & 5.064 & 0.057 & 0.052 & 0.151 & 0.303 \\
$\begin{array}{c}\text { Organizational norms -> Perceived } \\
\text { productivity }\end{array}$ & 0.142 & 0.044 & 3.252 & 0.075 & 0.025 & 0.066 & 0.214 \\
\hline
\end{tabular}

$R^{2}$ (organizational norms $=0.064 ;$ perceived productivity $=0.359 ;$ organizational commitment $=0.090$; job motivation $=0.046$ ).

Effect size impact indicator are according to Cohen [94], $f^{2}$ values: 0.35 (strong), 0.15 (moderate), and 0.02 (weak).

$Q^{2}$ (organizational norms $=0.062$; perceived productivity $=0.353$; organizational commitment $=0.084$; job motivation $=0.042$ ) .

Predictive relevance of predictor exogenous latent variables according to Henseler et al. [88,92], $q^{2}$ values: 0.35 (strong), 0.15 (moderate), and 0.02 (weak).

The relationships between the constructs of work demand, organizational norms on remote working, motivating potential, perceived productivity, and organizational commitment was examined. The results yielded several significant relationships, as illustrated in Figure 2.

Results revealed that work demand had a positively significant direct effect on perceived productivity $(\beta=0.547, t=14.665, p<0.001)$; therefore, hypothesis $1 \mathrm{~A}$ was supported. Hypothesis $1 \mathrm{~B}$ was not supported because work demand showed no significant effect on organizational commitment $(p>0.05)$. However, organizational norms revealed a signifi- 
cant mediating effect between work demand $(\beta=0.254, t=5.290, p<0.001)$ and perceived productivity $(\beta=0.142, t=3.252, p<0.001)$ and organizational commitment $(\beta=0.230$, $t=5.064, p<0.001)$. Hypothesis $1 \mathrm{C}$ and hypothesis $1 \mathrm{D}$ were supported.

Job motivation exhibited a significant mediating effect between work demand $(\beta=0.214, t=4.449, p<0.001)$ and organizational commitment $(\beta=0.169, t=3.232$, $p<0.001)$, but not on perceived productivity $(p>0.05)$. Therefore, hypothesis $2 \mathrm{~A}$ was not supported, whereas hypothesis $2 \mathrm{~B}$ was supported. Organizational norms did not have a significant effect on job motivation $(p>0.05)$, whereas job motivation only showed a significant effect on organizational commitment $(\beta=0.169, t=3.232, p<0.001)$. Consequently, hypothesis $2 \mathrm{C}$ and hypothesis $2 \mathrm{D}$ were not supported.

A test of indirect effect was conducted. The results indicated that work demand had a strong direct effect on perceived productivity $(\beta=0.547, t=14.665, p<0.001)$, which was greater than the indirect effect through organizational norms $(\beta=0.036, t=2.721, p<0.01)$. Moreover, work demand showed a slightly greater effect on organizational commitment through organizational norms $(\beta=0.059, t=3.515, p<0.001)$ than job motivation $(\beta=0.036$, $t=2.700, p<0.01$.

The structural model presented a standardized root mean square residual (SRMR) value of 0.032 and a normed fit index (NFI) value of 0.971 , indicating a good model fit with the recommended SRMR of less than 0.08 [88,96] and NFI greater than 0.9 [97]. The model fit analysis confirmed the significance of the reflective constructs and the relationship in the proposed model.

\section{Discussion}

\subsection{Employees' Perceived Productivity and Organizational Commitment}

This study proposed a mechanism model of perceived productivity and organizational commitment in a remote working context. The findings showed that perceived productivity could be significantly measured by three main constructs. Collaborative productivity performed the highest significance affecting employee's perceived productivity $(\beta=0.621)$, followed by productivity concentration $(\beta=0.515)$ and communication skill showed a comparatively very low level of effect $(\beta=0.002)$. Previous studies focused on communication skills in physical organizational contexts, such as open space, cellular office, and co-working space, to calibrate spatial influence on communication capacity $[98,99]$. On the other hand, the studies on remote working may explore ICTs or teleworking support for remote working communication to explain employees' communicational performance $[2,100]$. Therefore, productivity in the remote working context is less dependent on personal communication skills but better response through the work environment, activity, and tools that facilitate the communication process.

The model found organizational commitment attributed to affective commitment and continuance-normative commitment. Gellatly suggested the combination of commitment constructs could promote employees' organizational commitment and deliver more complex levels of work outcome [101]. However, the result was found contradictory to Gellatly's finding that explained the combination of affective commitment and normative commitment performed the highest influence among other combinations in the relation of work outcome and the turnover retention [101]. Instead, the present model proposed that, with the remote working implementation, a combination of continuance commitment and normative commitment performed the highest influence on employees' organizational commitment $(\beta=0.750)$ than that of affective commitment $(\beta=0.431)$ alone. Employees working remotely get limited physical interaction with co-workers. As a result, affective commitment became less critical in the remote working environment. However, during the COVID-19 pandemic, employees experienced more fear of losing their job for income to support their family's needs if they leave the organization, therefore cause a high level of continuance commitment to remain in the organization [51]. In addition, employees reported less work conflict in the remote working environment, drove a higher normative commitment willing to adapt to the difficulties and execute their obligation to the 
organization [102]. Somers [83] revealed that employees with high continuance-normative commitment performed the lowest absenteeism level compared to the other commitment constructs combination. This finding suggests that organizations prioritise continuancenormative commitment in remote working contexts to allow work flexibility for better work productivity and operation continuity, even during crisis.

\subsection{Organizational Norms and Job Motivation as Mediators}

The finding explained that organizational norms drive employees' perceived productivity. Organizational norms showed a positive mediating effect on the relationship between work demand and employees' perceived productivity. In comparison with the indirect effect of the mediator, work demand showed a significantly stronger direct effect on perceived productivity. The previous studies showed that a stable increment of work demand positively manipulated different employees' job performance and consequently influenced organization performance [8,103]. Kazekami [77] suggested that employees could perform better in their jobs to sustain business continuity with good control of work pace in a remote working operation. However, In the pandemic situation during this study, it can bring emotional challenges amongst organizations and their employees. HR operations have to make efforts to increase the level of commitment and motivation of their employees after introducing several changes in the organization. In such a condition, assigning employees with a certain extend of work demand can positively affect employees' organizational commitment. However, the finding found that work demand only significantly influenced organizational commitment through the mediating effect of organizational norms. This implicated the need to provide a remote working arrangement in the organization to ensure employees' organizational commitment while coping with the work demand. Eventually, introducing a remote working policy with good control of work demand would improve employees' organizational commitment and productivity. Guterresa and Armanu (2019) found that job motivation mediated the impact of leadership style, which is one of the core elements of organizational norms [61], on employee performance [104].

Job motivation revealed a significant mediating effect on the relationship between work demand and organizational commitment. Employees with high job motivation showed higher job performance [70]. With an increase in work demand, employees with the equivalent capability can perform the required work and feel motivated by the achieved outcome in return, consequently resulting in higher commitment. By contrast, organizational norms did not have a significant effect on job motivation. This finding is supported by Kamara et al. [105] that adaptive organizational norm derives from the external change, such as the physical environment and leadership, while motivation only derives from the internal incentives self-satisfaction and needs. Therefore, the organization ought to focus on providing skill training, knowledge sharing, and resource supporting that promote employees' internal incentives for better job motivation [106,107].

In conclusion, organizational norms are shown as a higher significant mediator as compared with job motivation. In past research, HR has emphasized the role of job motivation in organizational performance $[104,107]$. However, this study's finding showed that, from the FM perspective, organizational norms on remote working demonstrated higher efficiency in driving employees' productivity and organizational commitment. As such, the facility manager necessitates understanding the workplace transformation mechanism to deliver the organizational norms on remote working, which bring significant value to promote employees' productivity and organizational commitment.

\subsection{Implications}

\subsubsection{Theoretical Implication}

Firstly, this study developed a model to address the knowledge gap in understanding the mechanism of perceived productivity and organizational commitment in a remote working context. The finding discovered the significant mediating role of organizational 
norms on remote working. This significance offers a new measurement consideration and advances the body of knowledge on remote working in strategic FM. Secondly, the present study contributes to the valid measurement tool and model to assess remote working capability. Concerning organizational norms on remote working, the study provides a benchmarking reference for guiding organizations to better remote working performance. Thirdly, even though this study was done during the COVID-19 pandemic period, the model and measurement are also applicable to promote remote working transformational conditions.

\subsubsection{Practical Implication}

FM managers and organizations need to align the organizational strategy, operation, and norm into a uniform system FM manager should prioritize to promote remote working implication by FM practices. Firstly, the control of work pace, amount of work, and work continuity, which caused high quality in work demand, must be arranged in an organization to improve perceived productivity. FM may address the value-added perceived productivity on remote working towards work demand to top corporate management [108]. This could be more holistic and more accepted in implementing strategy in an organization. Additionally, the availability of flexible work demand is more in requirement during a crisis. FM must consider the ability to manage work demand importantly to retain employee's productivity [46]. Secondly, to maintain or increase the organizational commitment of remote work employees, the organization must build efficient organizational norms, namely remote work supervision, leadership support, and system functionary, to support the remote work environment [58,61,109]. For example, FM managers can consider remote working as a strategy to reflect employee retention in an organization. Lastly, in the past research on remote working and COVID-19, job motivation was usually focused by HR development on evaluating the impact of motivation on employee's commitment during remote work and crisis $[11,64,106]$. However, the result of this present study suggested that organizational norms presented as of higher importance. This could confirm that remote working performs well on organizational flexibility and balances individual skills in collaboration and concentration to accept a remote working application. Therefore, FM should reconsider using the HR factor as job motivation to identify the level of organizational commitment during remote work and crisis. HR should also consider using organizational norms in their employee's evaluation when organizations recognise remote working in their work context.

\subsection{Limitations and Future Research}

The present study aimed to explore organizational norms on remote working in corporate organizations. Unfortunately, due to the COVID-19 pandemic, access to physical asset management was limited during the officially adjusted remote work policy. Therefore, this study only focused on the impact of organizational norms from the employees' perspective. Future studies on physical asset management for remote working through simulation can further assist FM managers' decision-making to effectively implement remote work and enhance the sustainability of remote work transformation and the readiness of workplace shift when remote working is required. Besides, to leverage the measurement model of strategic FM, FM must require a collaboration with HR data to collectively identify and monitor performances of both physical and human factors in a remote working context. Such data present the FM policy's reliable performance, instead of measuring only physical performance or individuals' performance. Pre- and post-measurement on employees' feedback from policy impact or tracking remote work activities from technological and physical usage could be measured in the strategic FM research. This aspect could help stakeholders or corporate real estate make effective decisions on remote working. Additionally, remote working is not a new phenomenon. This norm's next direction offers an alternative future investment for stakeholders' consideration of business flexibility by reducing physical costs and allocating more technological development funds. Future research may require a 
substantial approach on FM or space management-related applications to simultaneously simulate work performance through physical office space and employees' activities. The present study was undertaken in Thailand, and the finding may be limited to cultural differences. Future study in other regions is strongly encouraged.

Lastly, this study also focuses on developing a model to address the gap in understanding the mechanism of perceived productivity and organizational commitment in a remote working context. The study acknowledges authors to explore the effect of the different dimensions on perceived productivity and organizational commitment in various workplace topology or during workplace transformation in the future study. The study's statistical method has a limitation on assessing PLS path model's predictive power [87] and the control for unobserved heterogeneity issues [110]. Hence, these techniques could be extended as a routine procedure for model predictive research in the future.

\section{Conclusions}

The impact of technological disruption and global economic change requires FM managers to adapt their organizational facility to respond to the consequences of workplace transformation. Many organizations responded to those impacts by launching remote working procedures. However, there is a limited understanding of what is the critical factors affecting their work performance. According to the FM previous approach, HR factors have not been noticed in workplace transformation in evaluating employee performance during remote work. Some organizations only remained on their existing organizational norms and continued on-site operation without remote work transformation, resulted in employees' signs of dissatisfaction [64] and reduced work performance [111]. This study aimed to explore the mediating effect of organizational norms on remote working and job motivation in the relationship between work demand on employees' productivity and organizational commitment in the remote working context. The finding discovered the significant mediating role of organizational norms on remote working which can contributes to the valid measurement model to assess remote working capacity. This study suggested that FM could develop efficient organizational norms on remote working to leverage organizational commitment and perceived productivity, even in during the COVID-19 pandemic. In addition, the job motivation as the HR factor still plays an important mediating role in affecting organization commitment when organization sustain work demand. To conclude, strategic FM approach cannot reach the most successful outcome without the inclusion of HR measures, as well as the support on remote working vision and implementation from other stakeholders. FM managers need to understand the physical and human factors in remote working context comprehensively for efficient strategy. Such understanding can close the gap between FM planning and workplace transformation caused by the rapid action needed on remote working.

Author Contributions: Conceptualization, W.T. and X.D.; methodology, W.T.; validation, W.T. and H.W.L.; formal analysis, H.W.L.; investigation, W.T.; data curation, W.T. and H.W.L.; writing—original draft preparation, W.T. and H.W.L.; writing—review and editing, W.T., H.W.L. and X.D.; visualization, W.T., H.W.L.; supervision, X.D.; project administration, W.T.; All authors have read and agreed to the published version of the manuscript.

Funding: This research was supported by CoreNet Global Education Fund.

Institutional Review Board Statement: Not applicable.

Informed Consent Statement: Not applicable.

Data Availability Statement: The data sets used and/or analysed during the current study are available from the corresponding author on reasonable request.

Acknowledgments: Our sincerest appreciation to Thailand Facility Management Association (TFMA) for supporting us many sources of information and professionals' contact. We are also thankful for the FM insight of Ayuthaporn (Ek) Buranakul and the encouragement from friends and family.

Conflicts of Interest: The authors declare no conflict of interest. 


\section{Appendix A}

Table A1. Questionnaires.

\begin{tabular}{|c|c|}
\hline Code & Questions \\
\hline & Work demand (WD) \\
\hline & Please rate your level of agreement on the statement below from 1 (strongly disagree) to 7 (strongly agree) \\
\hline WD2 & Recently, my daily work in the organization and team operation has continued. \\
\hline WD3 & Recently, my daily work in the organization and team operation has been flexible. \\
\hline \multirow[t]{3}{*}{ WD4 } & Recently, my daily workload has been carried out as usual. \\
\hline & Organizational norms of remote working $(\mathrm{ON})$ \\
\hline & Please rate your level of agreement on the statement below from 1 (strongly disagree) to 7 (strongly agree) \\
\hline ON3 & My organization has carefully involved remote work arrangement in the organization. \\
\hline ON4 & My organization has conducted technical training on remote work support. \\
\hline ON5 & My organization has encouraged employees to work remotely when necessary. \\
\hline ON6 & My organization has focused on alternative flexible work arrangements and emerging support technologies. \\
\hline ON7 & My leader influences the organizational dynamics of remote work. \\
\hline ON8 & My leader supports employees who face challenges in remote work. \\
\hline \multirow[t]{3}{*}{ ON9 } & $\begin{array}{c}\text { My leader facilitates the alignment between employees and organizational goals on remote work arrangement. } \\
\text { Organizational commitment (OC) }\end{array}$ \\
\hline & Please rate your level of agreement on the statement below from 1 (strongly disagree) to 7 (strongly agree) \\
\hline & Affective commitment (AC) \\
\hline AC3 & I feel I am part of this organization. \\
\hline \multirow[t]{2}{*}{$\mathrm{AC} 4$} & I feel emotionally attached to this organization. \\
\hline & Continuance-Normative commitment (CC-NC) \\
\hline CC3 & I feel that my organization needs me as much as I need them. \\
\hline NC1 & I do not think it is right to leave even if it were to my advantage. \\
\hline NC2 & This organization deserves my loyalty. \\
\hline \multirow[t]{4}{*}{ NC3 } & I feel obligated to my organization and would not leave my organization now. \\
\hline & Perceived productivity (PP) \\
\hline & Please rate your level of performance on the statement below from 1 (the least) to 7 (the highest) \\
\hline & Productivity concentration (PC) \\
\hline PC1 & My productivity concentration during remote work \\
\hline PC2 & My task management and delivery performance during remote work \\
\hline PC3 & My work-life balance during remote work \\
\hline \multirow[t]{2}{*}{ PC4 } & My overall satisfaction with my productivity during remote work \\
\hline & Collaborative productivity $(C P)$ \\
\hline $\mathrm{CP} 1$ & My discussion and brainstorming skills with the team during remote work \\
\hline CP2 & My collaborative skills in formal meetings during remote work \\
\hline $\mathrm{CP} 3$ & My project presentation skills during remote work \\
\hline \multirow[t]{2}{*}{$\mathrm{CP} 4$} & My overall satisfaction with the collaborative activities during remote work \\
\hline & Communication skill (CS) \\
\hline CS1 & My ability to deliver information through online channels during remote work \\
\hline CS2 & My ability to manage workflow during remote work \\
\hline CS3 & My ability to manage my work schedule during remote work \\
\hline \multirow[t]{4}{*}{ CS4 } & My overall satisfaction with the communication in remote work \\
\hline & Motivating potential score \\
\hline & Please rate your level of agreement on the statement below from 1 (strongly disagree) to 7 (strongly agree) \\
\hline & Skill Variety \\
\hline SV1 & My job requires me to perform a variety of tasks that involve different skill sets. \\
\hline SV2 & My job requires me to use a number of complex or high-level skills. \\
\hline \multirow[t]{2}{*}{ SV3 } & My job is simple and repetitive. (Reverse question) \\
\hline & Task Identity \\
\hline TK1 & My job involves doing a whole piece of work from beginning to the end. \\
\hline TK2 & My job provides me with the chance to finish the pieces of work I begin. \\
\hline \multirow[t]{3}{*}{ TK3 } & My job is arranged in a way that I do not get involved in an entire piece of work from \\
\hline & beginning to end. (Reverse question) \\
\hline & Task significance \\
\hline TS1 & The outcome of my job can significantly affect the lives and well-being of other people. \\
\hline TS2 & A lot of people can be affected by how well my job gets done. \\
\hline TS3 & My job is simple and repetitive. (Reverse question) \\
\hline
\end{tabular}


Table A1. Cont.

\begin{tabular}{cc}
\hline Code & Questions \\
\hline AU1 & Autonomy \\
AU2 & My job gives me almost complete responsibility for decisions on how and when the work is done. \\
AU3 & My job denies me any chance to use my personal initiative or judgment in carrying out the work. (Reverse question) \\
FB1 & Feedback \\
FB2 & My job is set up such that I receive almost constant 'feedback' as I work about how well I am doing. \\
FB3 & The job itself provides very few clues about whether I am performing well. (Reverse question) \\
\hline
\end{tabular}

\section{References}

1. Teo, T.S.H.; Lim, V.K.G.; Wai, S.H. An empirical study of attitudes towards teleworking among information technology (IT) personnel. Int. J. Inf. Manag. 1998, 18, 329-343. [CrossRef]

2. Campbell, J.; McDonald, C. Defining a conceptual framework for telework and an agenda for research in accounting and finance. Int. J. Bus. Inf. Syst. 2009, 4, 387-402. [CrossRef]

3. Chotipanich, S. Positioning facility management. Facilities 2004, 22, 364-372. [CrossRef]

4. Chotipanich, S.; Nutt, B. Positioning and repositioning FM. Facilities 2008, 26, 374-388. [CrossRef]

5. Chotipanich, S.; Lertariyanun, V. A study of facility management strategy: The case of commercial banks in Thailand. J. Facil. Manag. 2011, 9, 282-299. [CrossRef]

6. Kniery, D. Facility management: How a virtual model enabled a breakthrough for a high-tech company. J. Facil. Manag. 2002, 1, 16-30. [CrossRef]

7. White, A.D. Managing Facilities to enhance organizational performance. In RICS Guidance Note; RICS: Budapest, Hungary, 2013.

8. ILO. Teleworking during the COVID-19 Pandemic and beyond A Practical Guide; ILO Publications: Geneva, Switzerland, 2020.

9. Kark, K.; Kilpatrick, J.; Phillips, A.; Ciaramella, J.; Lillie, M. COVID-19 People, Technology, and the Path to Organizational Resilience; Deloitte: Quebec, QC, Canada, 2020.

10. McKinsey\&Company. How COVID-19 has pushed companies over the technology tipping point-and transformed business forever. In McKinsey Digital and Strategy \& Corporate Finance Practices; McKinsey \& Company: London, UK, $2020 ;$ p. 9.

11. Silva-C, A.; Montoya, R.I.A.; Valencia, A.J.A. The attitude of managers toward telework, why is it so difficult to adopt it in organizations? Technol. Soc. 2019, 59, 101133. [CrossRef]

12. Aempoo, U. Purchasing Decision Process for Co-Working Spaces in Thailand. In Faculty of Commerce and Accountancy; Thammasat University: Pathunthani, Thailand, 2016.

13. Jack, J. Strategic Facilities Management. Prop. Manag. 1994, 12, 40-43. [CrossRef]

14. Van der Voordt, T. Facilities management and corporate real estate management: FM/CREM or FREM? J. Facil. Manag. 2017, 15, 244-261. [CrossRef]

15. Khongouan, W. Public Opinions of Residents in Bangkok's Central Business District Towards Environmental Management in the BangkokComprehensive Plan of 203. J. Archit./Plan. Res. Study 2018, 1, 35-48.

16. Thanyawatpornkul, R.; Siengthai, S.; Johri, L.M. Employee's perspective towards strategy execution in facility management in Thailand. Facilities 2016, 34, 682-702. [CrossRef]

17. WHO. Coronavirus Disease 2019 (COVID-19) WHO Thailand Situation Report-28 March 2020; WHO: Bangkok, Thailand, 2020.

18. Parpart, E. Working from Home Is Here to Stay While Its Hybrid Model Is Becoming more Popular, Says Experts. Available online: https:/ / www.thaienquirer.com/18086/working-from-home-is-here-to-stay-while-its-hybrid-model-is-becoming-morepopular-says-experts (accessed on 10 October 2020).

19. Kate, P.T. $20 \%$ of Thai Companies Are Working from Home, Says PwC. Available online: https://www.pwc.com/th/en/press$\mathrm{room} /$ press-release/2020/press-release-26-08-20-en.html (accessed on 10 October 2020).

20. Ho, J.; Hui, D.; Kim, A.; Zhang, Y. Cautiously Optimistic: Chinese Consumer Behavior Post-COVID-19; McKinsey \& Company: Shanghai, China, 2020.

21. See, B.H.; Wardle, L. Teachers' Wellbeing and Workload during Covid-19 Lockdown; Evidence Centre for Education, Durham University: Durham, UK, 2020.

22. McKinsey\&Company. COVID-19: Briefing Materials, Global Health and Crisis Response. Available online: https://www. mckinsey.com (accessed on 11 July 2020).

23. Sahni, D.J. Impact of COVID-19 on Employee Behavior: Stress and Coping Mechanism During WFH (Work From Home) Among Service Industry Employees. Int. J. Oper. Manag. 2020, 1, 35-48. [CrossRef]

24. McKinsey\&Company. The Path to the Next Normal: Leading with Resolve through the Coronavirus Pandemic. Available online: https: / / www.mckinsey.com (accessed on 10 October 2020).

25. Ninaus, K.; Diehl, S.; Terlutter, R.; Chan, K.; Huang, A. Benefits and stressors-Perceived effects of ICT use on employee health and work stress: An exploratory study from Austria and Hong Kong. Int. J. Q. Stud. Health Well-Being 2015, 10, 28838. [CrossRef] [PubMed] 
26. Meyer, J.P.; Herscovitch, L. Commitment in the workplace: Toward a general model. Hum. Resour. Manag. Rev. 2001, 11, 299-326.

27. Chun, J.; Cho, J. Improvement of Productivity through the Control of Continuity and Variation of Work Flow in Building Space. J. Asian Archit. Build. Eng. 2018, 14, 89-96. [CrossRef]

28. Van Veldhoven, M.J.P.M.; Prins, J.; Van der Laken, P.A.; Dijkstra, L. QEEW2.0: 42 Short Scales for Survey Research on Work, Well-Being and Performance; SKB: Armsterdam, AJ, USA, 2015.

29. Nik Lah, N.M.I.; Mohammed, A.H.; Mohd Asmoni, M.N.A. Office Space Study: A Review from Facilities Management Context. J. Teknol. 2015, 75. [CrossRef]

30. Levin, A.C. Changing the role of workplace design within the business organisation: A model for linking workplace design solutions to business strategies. J. Facil. Manag. 2005, 3, 299-311. [CrossRef]

31. Errichiello, L.; Pianese, T. Organizational Control in the Context of Remote Work Arrangements: A Conceptual Framework. In Performance Measurement and Management Control: Contemporary Issues; Emarald Group Publishing Limited: Bingley, UK, 2016; pp. 273-305.

32. Hickey, D.; Tang, N. Theoretical and Applied Approaches to Remote Work for Academic Reference and Instruction Librarians. In Library Staffing for the Future; Emarald Group Publishing Limited: Bingley, UK, 2015; pp. 177-200.

33. Groen, B.A.C.; van Triest, S.P.; Coers, M.; Wtenweerde, N. Managing flexible work arrangements: Teleworking and output controls. Eur. Manag. J. 2018, 36, 727-735.

34. Tucker, M.; Pitt, M. Improving service provision through better management and measurement of customer satisfaction in facilities management. J. Corp. Real Estate 2010, 12, 220-233. [CrossRef]

35. de Leede, J.; Heuver, P. New Ways of Working and Leadership: An Empirical Study in the Service Industry. In New Ways of Working Practices; Emarald Group Publishing Limited: Bingley, UK, 2016; pp. 49-71.

36. Sullivan, R.L.; Rothwell, W.J.; Balasi, M.J.B. Organization development (OD) and change management (CM): Whole system transformation. Dev. Learn. Organ. Int. J. 2013, 27, 18-23. [CrossRef]

37. Khazanchi, S.; Sprinkle, T.A.; Masterson, S.S.; Tong, N. A Spatial Model of Work Relationships: The Relationship-Building and Relationship-Straining Effects of Workspace Design. Acad. Manag. Rev. 2018, 43, 590-609. [CrossRef]

38. Kraut, R.; Fussell, S.R.; Brennan, S.E.; Siege, J. Understanding Effects of Proximity on Collaboration: Implications for Technologies to Support Remote Collaborative Work. Distrib. Work 2002, 137-162. Available online: https:/ /www.semanticscholar.org/paper/ Understanding-Effects-of-Proximity-on-Collaboration-Kraut-Fussell/97f53a4ff1c3d07cf81fa9b0efcc3af333fc6c15 (accessed on 10 October 2020).

39. Nakrošiene, A.; Buciuniene, I.; Goštautaite, B. Working from home: Characteristics and outcomes of telework. Int. J. Manpow. 2019. [CrossRef]

40. Grant, C.A.; Wallace, L.M.; Spurgeon, P.C. An exploration of the psychological factors affecting remote e-worker's job effectiveness, well-being and work-life balance. Empl. Relat. 2013, 35, 527-546. [CrossRef]

41. Haynes, B.; Suckley, L.; Nunnington, N. Workplace productivity and office type. J. Corp. Real Estate 2017, 19, 111-138. [CrossRef]

42. Aguilera, A.; Lethiais, V.; Rallet, A.; Proulhac, L. Home-based telework in France: Characteristics, barriers and perspectives. Transp. Res. Part A Policy Pract. 2016, 92, 1-11. [CrossRef]

43. Gadeyne, N.; Verbruggen, M.; Delanoeije, J.; De Cooman, R. All wired, all tired? Work-related ICT-use outside work hours and work-to-home conflict: The role of integration preference, integration norms and work demands. J. Vocat. Behav. 2018, 107, 86-99. [CrossRef]

44. Lippe, T.V.D.; Lippényi, Z. Co-workers working from home and individual and team performance. New Technol. Work Employ. 2019, 35, 60-79. [CrossRef]

45. Michielsens, E.; Bingham, C.; Clarke, L. Managing diversity through flexible work arrangements: Management perspectives. Empl. Relat. 2013, 36, 49-69. [CrossRef]

46. Mee Choo, J.L.; Desa, N.M.; Abu Hassan Asaari, M.H. Flexible Working Arrangement toward Organizational Commitment and Work-Family Conflict. Stud. Asian Soc. Sci. 2016, 3. [CrossRef]

47. Meyer, J.P.; Stanley, D.J.; Jackson, T.A.; McInnis, K.J.; Maltin, E.R.; Sheppard, L. Affective, normative, and continuance commitment levels across cultures: A meta-analysis. J. Vocat. Behav. 2012, 80, 225-245. [CrossRef]

48. Allen, N.J.; Meyer, J.P. The measurement and antecedents of affective, continuance and normative commitment to the organization. J. Occup. Psychol. 1990, 63, 1-18. [CrossRef]

49. Solutions, J.C. Workplace Powered by Human Experience; Consume Science \& Analytics (CSA); Jones Lang LaSalle Inc.: Tokyo, Japan, 2017.

50. WEF. The Future of Jobs, Employment, Skills and Workforce Strategy for the Fourth Industrial Revolution. In Global Challenge In-sight Report; World Economic Forum: Geneva, Switzerland, 2016.

51. Machokoto, W. A Commitment under Challenging Circumstances: Analysing Employee Commitment during the Fight against Covid-19 in the Uk. Int. J. Adv. Res. 2020, 8, 516-522. [CrossRef]

52. Bakker, A.B.; Demerouti, E. The Job Demands-Resources model: State of the art. J. Manag. Psychol. 2007, 22, 309-328. [CrossRef]

53. Bakker, A.B.; Demerouti, E.; Verbeke, W. Using the job demands-resources model to predict burnout and performance. Hum. Resour. Manag. 2004, 43, 83-104. [CrossRef]

54. Bal, P.M.; Jansen, P.G.W. Workplace Flexibility across the Lifespan. In Research in Personnel and Human Resources Management; Emarald Group Publishing Limited: Bingley, UK, 2016; pp. 43-99. [CrossRef] 
55. Laurence, G.A.; Fried, Y.; Slowik, L.H. "My space": A moderated mediation model of the effect of architectural and experienced privacy and workspace personalization on emotional exhaustion at work. J. Environ. Psychol. 2013, 36, 144-152. [CrossRef]

56. Cummings, T.G.; Worley, C.G. Organization Development $\mathcal{E}$ Change, 9th ed.; Cengage Learning: Mason, OH, USA, 2008.

57. Wang, Y.-C.; Lin, S.-W.; Lee, C.-H. Conducting an Evaluation Framework for Disaster Management under Adaptive Organization Change in a School System. Sustainability 2020, 12, 6615. [CrossRef]

58. Criado, N.; Julián, V.; Botti, V.; Argente, E. A Norm-Based Organization Management System. In Coordination, Organizations, Institutions and Norms in Agent Systems V. COIN 2009; Padget, J., Ed.; Lecture Notes in Computer Science; Springer: Berlin/Heidelberg, Germany, 2010; Volume 6069, pp. 19-35.

59. Deloitte. Remote Work, The New Norm; Deloitte Touche Tohmatsu Limied: Deloitte, Ghana, 2020.

60. Huang, Y.-H.; Robertson, M.M.; Chang, K.-I. The Role of Environmental Control on Environmental Satisfaction, Communication, and Psychological Stress. Environ. Behav. 2016, 36, 617-637. [CrossRef]

61. Szczepańska-Woszczyna, K. Leadership and Organizational Culture as the Normative Influence of Top Management on Employee's Behaviour in the Innovation Process. Procedia Econ. Financ. 2015, 34, 396-402. [CrossRef]

62. Hackman, J.R.; Oldham, G.R. Motivation through the design of work: Test of a theory. J. Organ. Behav. Hum. Perform. 1976, 16, 250-279. [CrossRef]

63. Kongrukgreatiyos, K. Major Impact from COVID-19 to Thailand's Economy, Vulnerable Households, Firms. Available online: https: / / www.worldbank.org/en/news/press-release/2020/06/30/major-impact-from-covid-19-to-thailands-economyvulnerable-households-firms-report (accessed on 1 August 2020).

64. Baert, S.; Lippens, L.; Moens, E.; Sterkens, P.; Weytjens, J. How Do We Think the COVID-19 Crisis Will Affect Our Careers (If Any Remain)? IZA-Institute of Labor Economics: Bonn, Germany, 2020.

65. Berthelsen, H.; Muhonen, T.; Toivanen, S. What happens to the physical and psychosocial work environment when activity-based offices are introduced into academia? J. Corp. Real Estate 2018, 20, 230-243. [CrossRef]

66. Peiró, J.M.; Bayona, J.A.; Caballer, A.; Di Fabio, A. Importance of work characteristics affects job performance: The mediating role of individual dispositions on the work design-performance relationships. Personal. Individ. Differ. 2020, 157. [CrossRef]

67. Kundu, S.C.; Lata, K. Effects of supportive work environment on employee retention. Int. J. Organ. Anal. 2017, 25, 703-722. [CrossRef]

68. Sirikrai, S. Measurement of Organizational Culture: A Literature Review. Bus. Adm. J. 2006, 29, 39-52.

69. Wojcak, E.; Bajzikova, L.; Sajgalikova, H.; Polakova, M. How to Achieve Sustainable Efficiency with Teleworkers: Leadership Model in Telework. Procedia Soc. Behav. Sci. 2016, 229, 33-41. [CrossRef]

70. Bahrami, M.A.; Aghaei, A.; Barati, O.; Tafti, A.D.; Ranjbar Ezzatabadi, M. Job Motivating Potential Score and Its Relationship with Employees' Organizational Commitment among Health Professionals. Osong Public Health Res. Perspect. 2016. [CrossRef]

71. Wagner, J.A.; Hollenbeck, J.R. Organizational Behavior; Securing Competitive Advantage; Taylor \& Francis: New York, NY, USA, 2010.

72. Sveiby, K.E.; Simons, R. Collaborative climate and effectiveness of knowledge work-An empirical study. J. Knowl. Manag. 2002, 6, 420-433. [CrossRef]

73. Opoku, A.; Ahmed, V.; Cruickshank, H. Leadership style of sustainability professionals in the UK construction industry. Built Environ. Proj. Asset Manag. 2015, 5, 184-201. [CrossRef]

74. Fatma, I.K.A.; Abdul Kadir, S.; Sariman, T.; Yuliana, S. The Level of Wage and Labor Productivity in Hotel Industry: An Analysis. Eurasian J. Econ. Financ. 2017, 5, 36-50. [CrossRef]

75. UN. Living Arrangements of Older Persons around the World; United Nation Department of Economic and Social Affairs: New York, NY, USA, 2005.

76. ILO. Conclusions on skills for improved productivity, employment growth and development. In International Labour Conference; International Labour Office Geneva: Geneva, Switzerland, 2008.

77. Kazekami, S. Mechanisms to improve labor productivity by performing telework. Telecommun. Policy 2020, 44. [CrossRef]

78. Ringle, C.M.; Sarstedt, M.; Straub, D.W. Editor's Comments: A Critical Look at the Use of PLS-SEM in "MIS Quarterly". MIS Q. 2012, 36, iii-xiv. [CrossRef]

79. Fabrigar, L.; Wegener, D.; MacCallum, R.; Strahan, E. Evaluating the use of exploratory factor analysis in psychological research. Psychol. Methods 1999, 4, 272-299. [CrossRef]

80. Curran, P.; West, S.; Finch, J.F. The robustness of test statistics to nonnormality and specification error in confirmatory factor analysis. Psychol. Methods 1996, 1, 16-29. [CrossRef]

81. Kaiser, H. A second generation little jiffy. Psychometrika 1970, 35, 401-415. [CrossRef]

82. Hair, J.F.; Black, W.; Babin, B.J.; Anderson, R. Multivariate Data Analysis, 7th ed.; Pearson Publishing: Englewood Cliffs, NJ, USA, 1979.

83. Somers, M.J. The combined influence of affective, continuance and normative commitment on employee withdrawal. J. Vocat. Behav. 2009, 74, 75-81. [CrossRef]

84. Karim, A.; Noor, M. Evaluating the psychometric properties of Allen and Meyer's organizational commitment scale: A cross cultural application among Malaysian academic librarians. Malays. J. Libr. Inf. Sci. 2006, 11, 89-101.

85. Nunnally, J.; Bernstein, I.H. Psychometric Theory; McGraw-Hill: New York, NY, USA, 1994.

86. Fornell, C.; Larcker, D.F. Evaluating Structural Equation Models with Unobservable Variables and Measurement Error. J. Mark. Res. 1981, 18, 39-50. [CrossRef] 
87. Hair, J.F.; Risher, J.J.; Sarstedt, M.; Ringle, C.M. When to use and how to report the results of PLS-SEM. Eur. Bus. Rev. 2019, 31, 2-24. [CrossRef]

88. Henseler, J.; Dijkstra, T.K.; Sarstedt, M.; Ringle, C.; Diamantopoulos, A.; Straub, D.; Ketchen, D.; Hair, J.F.; Hult, G.; Calantone, R. Common Beliefs and Reality About Partial Least Squares: Comments on Rönkkö \& Evermann. J. Org. Res. Method 2014. [CrossRef]

89. Henseler, J.; Ringle, C.M.; Sarstedt, M. A new criterion for assessing discriminant validity in variance-based structural equation modeling. J. Acad. Mark. Sci. 2015, 43, 115-135. [CrossRef]

90. Kock, N. Common method bias in PLS-SEM: A full collinearity assessment approach. Int. J. e-Collab. 2015, 11, 1-10. [CrossRef]

91. Hair, J.F.; Hult, G.T.M.; Ringle, C.M.; Sarstedt, M. A Primer on Partial Least Squares Structural Equation Modeling (PLS-SEM), 2nd ed.; SAGE Publishing: Thousand Oaks, CA, USA, 2017.

92. Henseler, J.; Ringle, C.M.; Sinkovics, R.R. The use of partial least squares path modeling in international marketing. In New Challenges to International Marketing; Emarald Group Publishing Limited: Bingley, UK, 2009; pp. 277-319.

93. Hair, J.F., Jr.; Sarstedt, M.; Hopkins, L.; Kuppelwieser, V.G. Partial least squares structural equation modeling (PLS-SEM). Eur. Bus. Rev. 2014, 26, 106-121. [CrossRef]

94. Cohen, J. Statistical Power Analysis for the Behavioral Sciences, 2nd ed.; Taylor \& Francis Group: New York, NY, USA, 1988.

95. Fornell, C.; Cha, J. Partial Least Square; Bagozzi, R.P., Ed.; Advanced Methods in Marketing Research; Cambridge: Worcestershire, UK, 1994; pp. 52-87.

96. Hu, L.-T.; Bentler, P. Fit indices in covariance structure modeling: Sensitivity to underparameterized model misspecification. Psychol. Methods 1998, 3, 424-453. [CrossRef]

97. Bentler, P.; Bonett, D. Significance Tests and Goodness of Fit in the Analysis of Covariance Structures. Psychol. Bull. 1980, 88, 588-606. [CrossRef]

98. Kleasen, K.J.; Foster, A. Communication strategies for the transition of employees to an open work environment. J. Facil. Manag. 2002, 1, 201-213. [CrossRef]

99. Nipe, E. Office Design in Relation to Perceived Indoor Climate, Communication Climate, and Work Engagement. Master's Thesis, Lunds Universitet, Lund, Sweden, 2016.

100. Hynes, M. Developing (tele)work? A multi-level sociotechnical perspective of telework in Ireland. Res. Transp. Econ. 2016, 57, 21-31. [CrossRef]

101. Gellatly, I.R.; Meyer, J.P.; Luchak, A.A. Combined effects of the three commitment components on focal and discretionary behaviors: A test of Meyer and Herscovitch's propositions. J. Vocat. Behav. 2006, 69, 331-345. [CrossRef]

102. Norman, C.S.; Hunton, J.E. The Impact of Alternative Telework Arrangements on Organizational Commitment: Insights from a Longitudinal Field Experiment (Retracted). J. Inf. Syst. 2010, 24, 67-90.

103. Baert, S.; Lippens, L.; Moens, E.; Sterkens, P.; Weytjens, J. The COVID-19 Crisis and Telework: A Research Survey on Experiences, Expectations and Hopes; IZA-Institute of Labor Economics: Bonn, Germany, 2020.

104. Guterresa, L.F.D.C.; Armanu, A.; Rofiaty, R. The role of work motivation as a mediator on the influence of education-training and leadership style on employee performance. Manag. Sci. Lett. 2020, 1497-1504. [CrossRef]

105. Kamara, J.M.; Heidrich, O.; Tafaro, V.E.; Maltese, S.; Dejaco, M.C.; Re Cecconi, F. Change Factors and the Adaptability of Buildings. Sustainability 2020, 12, 6585. [CrossRef]

106. Irakoze, E.; David, K.G. Linking Motivation to Employees' Performance: The Mediation of Commitment and Moderation of Delegation Authority. Int. Bus. Res. 2019, 12. [CrossRef]

107. Evelyne, N. Mediating Effect of Motivation on Employees Performance in Private Equity Firms, Kenya. J. Hum. Resour. Manag. 2018, 6. [CrossRef]

108. Jensen, P.A. Facilities Management and Added Value: An EuroFM Research Initiative; Euro FM Initiative: The Hague, The Netherland, 2010.

109. Olson, M.H. An Investigation of the Impacts of Remote Work Environments and Supporting Technology; Center for Digital Economy Research, Stem School of Business: New York, NY, USA, 1987.

110. Hair, J.J.F.; Sarstedt, M.; Matthews, L.M.; Ringle, C.M. Identifying and treating unobserved heterogeneity with FIMIX-PLS: Part I-Method. Eur. Bus. Rev. 2016, 28, 63-76. [CrossRef]

111. Murphy, T.; Akehurst, H.; Mutimer, J. Impact of the 2020 COVID-19 pandemic on the workload of the orthopaedic service in a busy UK district general hospital. Injury 2020, 51, 2142-2147. [CrossRef] 